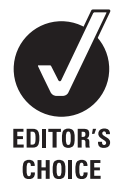

${ }^{1}$ School of Health and Related Research (ScHARR), University of Sheffield, Sheffield, UK 2Departments of Clinical Blood Sciences and Cardiology, St George's Hospital, London, UK ${ }^{3}$ Emergency Department, Royal Infirmary of Edinburgh, Edinburgh, UK

${ }^{4}$ Institute of Genetics, Health and Therapeutics, University of Leeds, Leeds, UK

Correspondence to Professor Steve Goodacre, University of Sheffield, Regent Court, 30 Regent Street, Sheffield S1 4DA, UK s.goodacre@sheffield.ac.uk

*For members of the RATPAC research team see the end of the paper.

Accepted 27 July 2010 Published Online First 30 September 2010

\title{
The Randomised Assessment of Treatment using Panel Assay of Cardiac Markers (RATPAC) trial: a randomised controlled trial of point-of-care cardiac markers in the emergency department
}

\author{
Steve W Goodacre, ${ }^{1}$ Mike Bradburn, ${ }^{1}$ Elizabeth Cross, ${ }^{1}$ Paul Collinson, ${ }^{2}$ \\ Alasdair Gray, ${ }^{3}$ Alistair S Hall, ${ }^{4}$ on behalf of the RATPAC Research Team*
}

\begin{abstract}
Objectives To determine whether using a point-of-care cardiac biomarker panel would increase the rate of successful discharge home after emergency department assessment, and affect the use of cardiac tests and treatments, subsequent attendance at or admission to hospital and major adverse events.
\end{abstract}

Design and setting Pragmatic multicentre randomised controlled trial in six acute hospitals in the UK.

Participants Patients attending with acute chest pain due to suspected myocardial infarction $(N=2243)$.

Interventions Diagnostic assessment using a point-ofcare biomarker panel consisting of creatine kinase, myocardial type, myoglobin and troponin I measured at baseline and 90 min compared with standard care without the point-of-care panel.

Main outcome measures The primary outcome was successful discharge home, defined as having left hospital or awaiting transport home by $4 \mathrm{~h}$ after attendance and no major adverse events up to 3 months. Secondary outcome measures included length of stay, use of coronary care, cardiac interventions and inpatient beds, emergency department attendances, subsequent admissions, outpatient visits and major adverse events. Results Point-of-care panel assessment was associated with an increased rate of successful discharge (358/ 1125 (32\%) vs 146/1118 (13\%); OR 3.81, 95\% Cl 3.01 to 4.82; $p<0.001)$, reduced median length of initial hospital stay (8.8 vs $14.2 \mathrm{~h} ; \mathrm{p}<0.001$ ) and greater use of coronary care $(50 / 1125(4.0 \%)$ vs $31 / 1118(3.0 \%)$; $\mathrm{p}=0.041)$, but no difference in mean length of initial stay (29.6 vs $31.7 h ; p=0.462$ ), mean inpatient days over follow-up (1.8 vs $1.7 ; p=0.815$ ) or major adverse events (36 (3\%) vs $26(2 \%)$; OR 1.31, 95\% Cl 0.78 to 2.20 ; $\mathrm{p}=0.313$ )

Conclusions Point-of-care panel assessment increases successful discharge home and reduces median length of stay, but does not alter overall hospital bed use.

Trial registration Current controlled trials ISRCTN37823923.

The rise in hospital admissions has recently been described as a problem that 'threatens bankruptcy for the NHS'. ${ }^{1}$ Chest pain is responsible for approximately a quarter of emergency hospital admissions ${ }^{2}$ and recent developments are adding to the problem. The main reason for hospital attendance is the possibility of acute myocardial infarction. Recent public information campaigns have encouraged patients to call for an emergency ambulance if they have acute chest pain. However, current recommendations suggest that diagnosis requires testing with a troponin sample taken $10-12 \mathrm{~h}$ after their symptom onset. ${ }^{3} 4$ This approach requires many patients to be unnecessarily admitted to hospital until the time delay has elapsed, thus incurring additional health service costs and inconvenience for patients.

It has been suggested that the cardiospecificity of troponin measurement should be combined with other biomarkers that are released earlier to facilitate rapid diagnosis. Combined measurement of cardiac troponin, myoglobin and the $\mathrm{MB}$ isoenzyme of creatine kinase (myocardial type; CK-MB) as a cardiac panel has been proposed as a way combining early and later markers. Recently developed sensitive troponin assays may further improve the early sensitivity of diagnostic testing, ${ }^{56}$ thus allowing the rapid rule-out of myocardial infarction and avoidance of admission, although this has yet to be tested in practice.

Point-of-care testing can substantially reduce turnaround time and allow rapid provision of results to the emergency department. The combination of cardiac troponin, $\mathrm{CK}-\mathrm{MB}$ and myoglobin measured by point-of-care testing at baseline and 90 min later has been widely evaluated and used. Diagnostic cohort studies of this combination report high sensitivity for myocardial infarction ${ }^{7-14}$ and before-and-after intervention studies suggest its use can reduce turnaround times ${ }^{10}$ and coronary care unit admissions. ${ }^{11}$ However, there have been no randomised controlled trials of this diagnostic strategy to determine reliably whether it can change patient management and reduce hospital admissions.

Although point-of-care cardiac marker panels have clear theoretical benefits, pragmatic evaluation is required to determine whether the rapid availability of accurate diagnostic information leads to changes in clinical decision-making and patient management. The Randomised Assessment of Treatment using Panel Assay of Cardiac markers (RATPAC) trial aimed to measure the effect of using a point-of-care cardiac marker panel upon discharge home after emergency department assessment, use of coronary and intensive care and cardiac treatments, subsequent re-attendance at and/or re-admission to hospital and major adverse events. 


\section{METHODS}

We undertook a pragmatic randomised controlled trial of a point-of-care cardiac marker panel in the management of patients with suspected, but not confirmed, myocardial infarction in six emergency departments in the UK: Barnsley District General Hospital, Derriford Hospital (Plymouth), Edinburgh Royal Infirmary, Frenchay Hospital (Bristol), Leeds General Infirmary and Leicester Royal Infirmary. We selected hospitals that would provide a diverse range of settings, were able to support point-of-care testing in the emergency department, did not already use a point-of-care cardiac marker panel and were able to support emergency care research. Research nurses or emergency department staff screened all patients with chest pain and excluded those with electrocardiogram (ECG) changes for myocardial infarction or high-risk acute coronary syndrome ( $>1 \mathrm{~mm}$ ST deviation or $>3 \mathrm{~mm}$ inverted $\mathrm{T}$ waves), known coronary heart disease (CHD) presenting with prolonged $(>1 \mathrm{~h}$ ) or recurrent episodes of cardiac-type pain, confirmed or suspected serious non-coronary pathology (eg, pulmonary embolus), co-morbidity or social problems that require hospital admission, an obvious non-cardiac cause (eg, pneumothorax or muscular pain), more than $12 \mathrm{~h}$ since their most significant episode of pain, previous participants, those unable to understand the trial information and those unwilling to consent. Research nurses recorded details of all excluded patients during every fourth week of the trial.

Research nurses or emergency department staff provided trial information and obtained written consent. Participants were then randomly allocated to receive either: (1) diagnostic assessment using the point-of-care biomarker panel; or (2) standard care without the panel, according to a simple randomisation sequence, stratified by centre, generated by the Nottingham Clinical Trials Unit and accessed through a secure website. The allocated treatment group was only revealed after the participant's details were entered, written consent was confirmed and the participant irrevocably entered into the trial.

Patients in the intervention arm received testing with the point-of-care panel, while all other tests and treatments were available as normal. RATPAC was a pragmatic trial so the pointof-care test was provided with a recommended protocol for use but management decisions were ultimately at the discretion of the clinical staff and all other diagnostic tests and the use of laboratory blood tests in the control group were at the discretion of the clinical staff. Awareness of the intervention was essential to its implementation so there was no attempt to blind clinical staff, patients or carers to the allocated treatment group.

The point-of-care cardiac marker panel comprised CK-MB (mass), myoglobin and troponin I, measured at presentation and 90 min later, using the Siemens Stratus CS analyser (Siemens Healthcare Diagnostics, Frimley, UK). ${ }^{15}$ The analytical characteristics of the assays were as follows: troponin I detection limit $0.02 \mu \mathrm{g} / \mathrm{l}$, analytical range $0.02-50 \mu \mathrm{g} / \mathrm{l}$, interassay coefficient of variation (CV) $4.3-5.1 \%(0.03-0.22 \mu \mathrm{g} / \mathrm{l})$. The 99 th centile of the assay is $0.07 \mu \mathrm{g} / \mathrm{l}$. Myoglobin: detection limit $1 \mu \mathrm{g} / \mathrm{l}$; analytical range $1-900 \mu \mathrm{g} / \mathrm{l}$; interassay CV $1.9-12.7 \%$ (56-308 $\mu \mathrm{g} / \mathrm{l}) ; 95 \%$ reference interval, men 21 to $98 \mu \mathrm{g} / \mathrm{l}$, women 19 to $56 \mu \mathrm{g} / \mathrm{l}$, combined 20 to $82 \mu \mathrm{g} / \mathrm{l}$. CK-MB: detection limit $0.3 \mu \mathrm{g} / \mathrm{l}$; analytical range $0.3-150 \mu \mathrm{g} / \mathrm{l}$; interassay $\mathrm{CV}$ $0.15-1.27 \% \quad(3.7-39.3 \mu \mathrm{g} / \mathrm{l}) ; 95 \%$ reference interval 0.6 to $3.5 \mu \mathrm{g} / \mathrm{l}$.

Clinical staff were trained to use the test and given guidance in interpretation of the results. We provided guidance that advised a first panel test immediately after initial emergency department assessment and a second panel test 90 min later. Initially the guidance recommended hospital admission if any troponin level exceeded $0.02 \mu \mathrm{g} / \mathrm{l}$, if any CK-MB level exceeded $5 \mu \mathrm{g} / \mathrm{l}$, if the CK-MB gradient exceeded $1.6 \mu \mathrm{g} / \mathrm{l}$ or if the myoglobin gradient exceeded $25 \%$ of the initial level. The troponin threshold was amended during the trial in the light of recommendations that the 99th percentile should be used as a diagnostic threshold for myocardial infarction to recommend admission if either sample level exceeded $0.07 \mu \mathrm{g} / 1$ or if the first sample was less than $0.03 \mu \mathrm{g} / \mathrm{l}$ and the second was between 0.03 and $0.07 \mu \mathrm{g} / 1$.

The standard care group was managed without point-of-care testing, according to existing guidance at each hospital. One hospital used a troponin T assay with a diagnostic threshold of less than $0.01 \mu \mathrm{g} / \mathrm{l}$ measured $6 \mathrm{~h}$ after worst symptoms, whereas the other hospitals used troponin I assays with a diagnostic threshold ranging from less than 0.05 to less than $0.2 \mu \mathrm{g} / \mathrm{l}$ measured at $12 \mathrm{~h}$ after worst symptoms. Two hospitals admitted patients to an inpatient ward, one to a medical assessment unit and three to a clinical decision unit.

The primary outcome was the proportion of patients successfully discharged home after emergency department assessment, ie, discharged and having no adverse event (as defined below) during the following 3 months. To be defined as discharged the patient had to have left the hospital by $4 \mathrm{~h}$ after arrival or be awaiting transport home from hospital with a discharge decision made. This outcome was chosen because hospital admission is inconvenient for the patient and costly for the health service, so reducing the probability of admission would represent a meaningful benefit from rapid diagnostic testing. The 4-h time limit was chosen because the participating hospitals were subject to a national target of discharging patients from the emergency department within $4 \mathrm{~h}$ of arrival. Secondary outcomes included use of the coronary care unit, cardiac medications and cardiac interventions, re-attendance at and/or re-admission to hospital over the following 3 months and adverse events (death, non-fatal myocardial infarction according to the universal definition, ${ }^{16}$ emergency revascularisation, lifethreatening arrhythmia or hospitalisation for myocardial ischaemia). We also measured patient satisfaction, health utility, healthcare costs and the proportion of patients admitted with myocardial infarction, although these will be reported elsewhere (S Goodacre, M Bradburn, P Fitzgerald, et al, submitted January 2010).

Recruiting staff recorded baseline data, the results of initial assessment and emergency department disposition. Research nurses then used emergency department and hospital inpatient notes to record management decisions at initial attendance and admission, extract resource use data and identify subsequent hospital attendances or admissions and adverse events up to 3 months. Participants were mailed a questionnaire at 1 and 3 months to identify adverse events and hospital attendances, health and social care resource use, and measure EQ-5D and satisfaction with care.

Initial plans were to recruit 3130 participants to the trial. Previous data suggested that $50 \%$ of the routine care group would be successfully discharged. ${ }^{17}$ With 1565 evaluable subjects in each arm the trial would have $80 \%$ power to detect a $5 \%$ improvement (to $55 \%$ of patients successfully discharged) at the two-sided significance level of $5 \%$. The same sample size provided $80 \%$ power to detect a reduction from $4 \%$ to $2 \%$ in major adverse events, again at the two-sided $5 \%$ level of significance. 
Recruitment was terminated early after the funders declined a request for additional resources to continue the trial, having taken into account a conditional power calculation from the Data Monitoring Committee. This estimated the conditional power to detect a significant difference in the primary outcome was greater than $99.9 \%$ and the conditional power to detect a difference in the adverse event rate was less than $10 \%$, thus suggesting grounds for termination on the basis of futility (ie, further enrolment would not significantly improve the statistical power).

We analysed the primary outcome through logistic regression, fitting concurrently with intervention group the effects of centre, age, gender and past history of CHD to present adjusted OR along with their corresponding $95 \%$ CI. Analysis was on an intention to treat basis.

\section{RESULTS}

We recruited 2263 participants between 30 January 2007 and 2 June 2008. There were a total 2658 hospital-days of recruitment with a mean of 0.9 patients recruited per hospital per day. Over 667 hospital-days of screening we identified 9109 patients with chest pain, of whom 1295 (14\%) had ECG changes, $1378(15 \%)$ had known CHD with prolonged or recurrent pain, 724 (8\%) had suspected serious non-CHD pathology, 414 (5\%) had comorbidities or social problems mandating hospital admission, 2506 (28\%) had obvious non-cardiac pain, 465 (5\%) had over $12 \mathrm{~h}$ since their worst pain, $21(<1 \%)$ had previously participated, $109(1 \%)$ were unable to understand trial information, $198(2 \%)$ had other exclusion criteria, $240(3 \%)$ had an unknown reason for exclusion, $40(<1 \%)$ declined consent, $1115(12 \%)$ were eligible but recruitment was not sought and $604(7 \%)$ were recruited.

Table 1 shows the baseline characteristics of the study groups and figure 1 shows the flow of recruited patients through the trial. Some 140 patients $(12.4 \%)$ in the point-of-care group did not receive point-of-care testing as recommended: 34 did not receive any point-of-care testing, mostly due to problems using the technology, while the remainder received point-of-care in combinations other than those recommended. Two patients $(0.2 \%)$ in the standard care group received point-of-care testing.

In the point-of-care group 362 patients were initially discharged (319 had left the emergency department and 43 were awaiting transport by $4 \mathrm{~h}$ ), but four re-attended with a major adverse event, so overall 358/1125 (32\%) were successfully discharged. In the standard care group 147 patients were initially discharged (134 had left and 13 were awaiting transport), but one re-attended with a major adverse event, so overall 146/1118 $(13 \%)$ were successfully discharged. Point-of-care testing was associated with a significant increase in successful discharge (OR $3.81,95 \%$ CI 3.01 to $4.82 ; \mathrm{p}<0.001)$. Figure 2 shows that the difference in the proportion in hospital lasted until approximately $24 \mathrm{~h}$ after attendance.

Table 2 shows initial care provided in the first $24 \mathrm{~h}$. Patients receiving point-of-care were more likely to be admitted to the coronary care unit and receive clopidogrel, whereas patients receiving standard care were more likely to receive aspirin.

The mean length of the initial hospital stay was $29.6 \mathrm{~h}$ in the point-of-care group and $31.8 \mathrm{~h}$ in the standard care group (mean difference $2.2 \mathrm{~h}, 95 \%$ CI-3.7 to $8.0 ; \mathrm{p}=0.462$ (t-test)). The median length of initial hospital stay was markedly shorter than the mean and was shorter in the point-of-care arm: $8.8 \mathrm{~h}$ for the point-of-care group and $14.2 \mathrm{~h}$ for the standard care group $(p<0.001$, equality-of-medians test).
Table 1 Patient demographics and characteristics

\begin{tabular}{|c|c|c|}
\hline & $\begin{array}{l}\text { Point-of-care } \\
(\mathrm{N}=1125)\end{array}$ & $\begin{array}{l}\text { Standard care } \\
(\mathrm{N}=1118)\end{array}$ \\
\hline Mean age, years (SD) & $54.5(13.8)$ & $54.6(14.4)$ \\
\hline Median age, years (IOR) & $53.4(44-64)$ & $53.1(44-64)$ \\
\hline Min-max age, years & 22,93 & 23,96 \\
\hline Male & $683(61 \%)$ & $624(56 \%)$ \\
\hline Female & $442(39 \%)$ & 494 (44\%) \\
\hline
\end{tabular}

\section{Centre}

Barnsley District General Hospital $\quad 162(14 \%) \quad 164(15 \%)$

Derriford Hospital, Plymouth $\quad 164(15 \%) \quad 164(15 \%)$

Edinburgh Royal Infirmary $\quad 228(20 \%) \quad 224(20 \%)$

Frenchay Hospital, Bristol $233(21 \%) \quad 231(21 \%)$

Leeds General Infirmary $\quad 173(15 \%) \quad 171(15 \%)$

Leicester Royal Infirmary $\quad 165(15 \%) \quad 164(15 \%)$

Past history of CHD

$\begin{array}{lll}\text { No } & 985(88 \%) & 973(88 \%) \\ \text { Yes } & 132(12 \%) & 137(12 \%) \\ \text { Previous MI } & 60(5 \%) & 65(6 \%) \\ \text { Angina plus positive diagnostic test } & 46(4 \%) & 53(5 \%) \\ \text { CABG surgery } & 12(1 \%) & 15(1 \%) \\ \text { Angioplasty } & 37(3 \%) & 34(3 \%) \\ \begin{array}{l}\text { Stenosis }>50 \% \text { on coronary } \\ \text { angiography }\end{array} & 14(1 \%) & 12(1 \%) \\ \text { Unproved clinical label of CHD } & 36(3 \%) & 31(3 \%) \\ \text { Other } & 12(1 \%) & 10(1 \%)\end{array}$

Risk factors

Diabetes

Hypertension

$86(8 \%) \quad 92(8 \%)$

Hyperlipidaemia

$376(34 \%)$

$361(33 \%)$

Present smoker

$271(26 \%)$

$282(27 \%)$

Ex-smoker-last 10 years

$310(28 \%)$

$316(29 \%)$

Cocaine abuse

$144(13 \%)$

$129(12 \%)$

First-degree relative with angina or $\mathrm{Ml}$, onset age $<60$ years

$6(1 \%)$

$10(1 \%)$

$352(34 \%)$

Source of referral

$\begin{array}{lll}\text { General practitioner } & 188(17 \%) & 189(17 \%) \\ \text { Emergency ambulance } & 481(43 \%) & 510(46 \%) \\ \text { Self-referred } & 419(37 \%) & 375(34 \%) \\ \text { Other } & 35(3 \%) & 41(4 \%)\end{array}$

CABG, coronary artery bypass grafting; $C H D$, coronary heart disease; IQR, interquartile range; $\mathrm{Ml}$, myocardial infarction.

Table 3 shows the total number of days spent in hospital over the 3-month follow-up and the number of days spent on the coronary care or intensive care unit, including the initial hospital admission. We only recorded an inpatient day if the patient stayed overnight, so a proportion of patients were recorded as having no inpatient days if their initial hospital visit did not result in an overnight stay and they were not admitted on a subsequent occasion. More patients in the point-of-care group had no inpatient days $(54 \%$ vs $40 \%$; $p<0.001)$ but there was no difference in mean inpatient days. Figure 3 shows that these data are highly skewed with a few patients having many inpatient days. The point-of-care group had more patients with very long stays. This attenuated the effect on mean inpatient days of having a greater proportion with no hospital stay. Point-of-care testing was also associated with a higher use of coronary care ( $4 \%$ vs $3 \%$ ), although only a small minority of patients received any coronary or intensive care. 
Figure 1 Flow of patients through the trial.

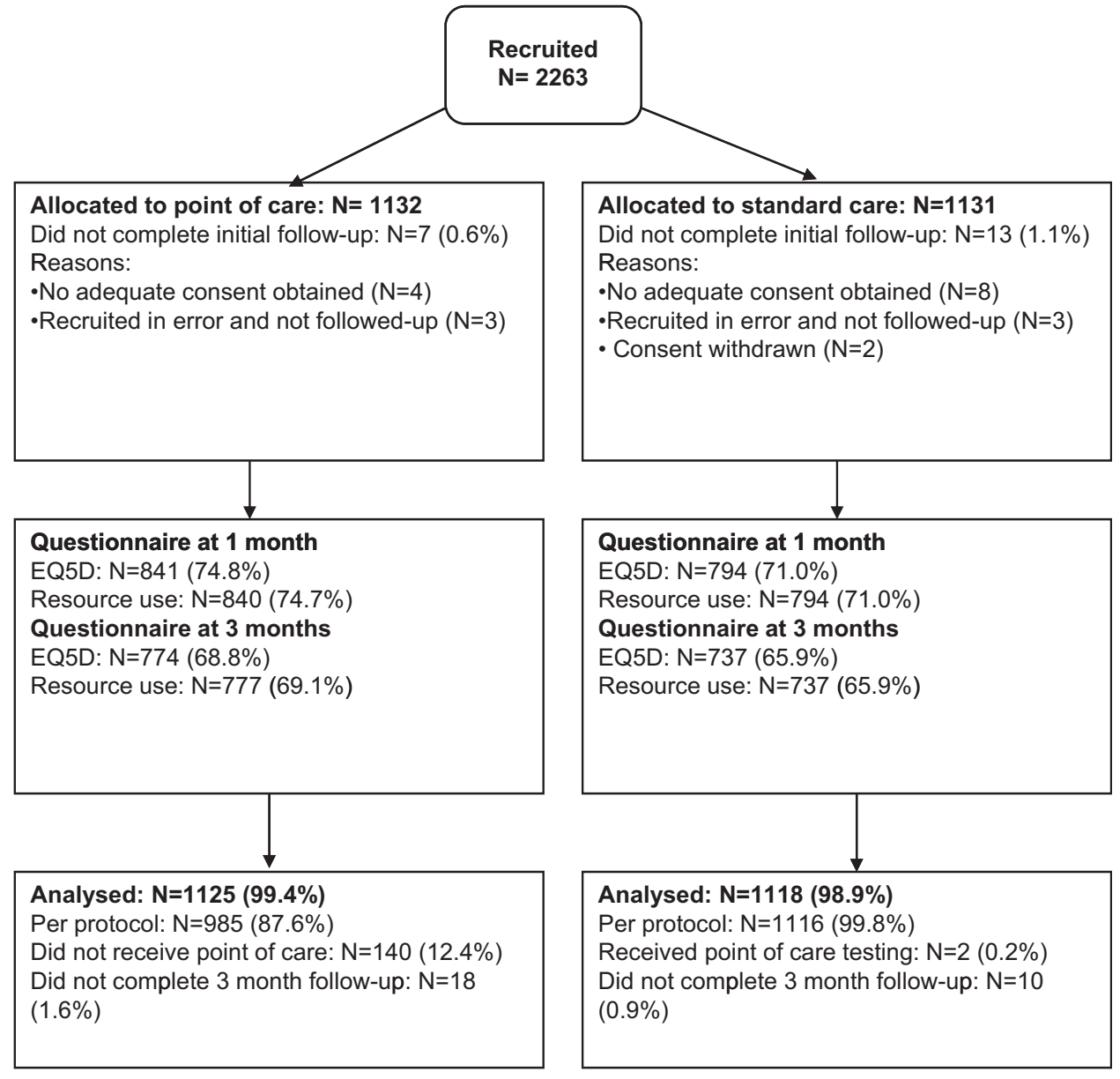

Table 4 shows cardiac interventions, emergency department attendances, hospital admissions (excluding admission at initial attendance) and outpatient reviews over the 3-month follow-up. The only difference between the groups was a borderline significant difference in chest pain-related outpatient attendances.

Overall 62 of 2243 patients (3\%) experienced an adverse event, including eight deaths and 10 non-fatal myocardial infarctions. Table 5 shows that there were no significant differences in major adverse events between the two groups. Five adverse events

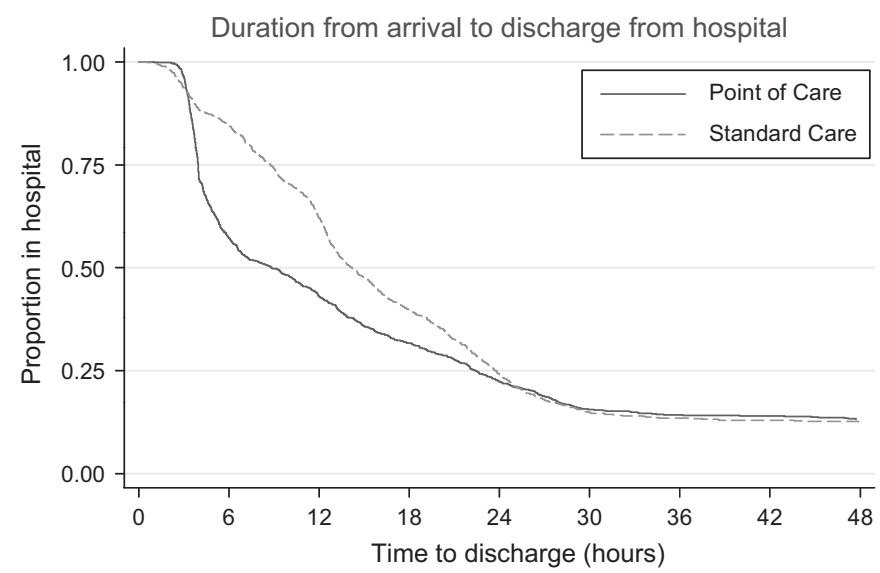

Figure 2 Variation in the proportion of patients in hospital over time from initial attendance. occurred in patients who were discharged home after emergency department assessment. Details are provided in table 6

\section{DISCUSSION}

The use of the point-of-care cardiac marker panel resulted in a greater proportion of patients being successfully discharged after emergency department assessment and a reduction in the median, but not the mean length of initial hospital stay. It was associated with more patients avoiding any inpatient stay over the 3-month follow-up but did not lead to any difference in the total or mean number of inpatient hospital days. This was

Table 2 Initial care in the first $24 \mathrm{~h}$

\begin{tabular}{llll}
\hline & $\begin{array}{l}\text { Point-of-care } \\
\text { N=1125 }\end{array}$ & $\begin{array}{l}\text { Standard care } \\
\mathbf{N}=1118\end{array}$ & p Value \\
\hline Admitted to coronary care unit & $50 / 1121(4 \%)$ & $21 / 1114(2 \%)$ & 0.001 \\
Received GTN & $446 / 1113(40 \%)$ & $460 / 1092(42 \%)$ & 0.327 \\
Received heparin & $206 / 1114(18 \%)$ & $186 / 1090(17 \%)$ & 0.381 \\
Received glycoprotein inhibitors & $8 / 1111(1 \%)$ & $7 / 1092(1 \%)$ & 0.822 \\
Received antacid & $90 / 1110(8 \%)$ & $108 / 1083(10 \%)$ & 0.128 \\
Received angiography & $16 / 1119(1 \%)$ & $8 / 1109(1 \%)$ & 0.105 \\
Received aspirin & $618 / 1118(55 \%)$ & $663 / 1109(60 \%)$ & 0.031 \\
Received beta-blocker & $108 / 1109(10 \%)$ & $105 / 1084(10 \%)$ & 0.967 \\
Received clopidogrel & $237 / 1110(21 \%)$ & $176 / 1091(16 \%)$ & 0.002 \\
Received analgesic & $373 / 1110(34 \%)$ & $407 / 1086(37 \%)$ & 0.058 \\
Received any other drugs & $316 / 1108(29 \%)$ & $340 / 1085(31 \%)$ & 0.150 \\
Received coronary angioplasty & $11 / 1120(1 \%)$ & $4 / 1108(<1 \%)$ & 0.073 \\
or stent & & & \\
\hline
\end{tabular}

GTN, glyceryl trinitrate. 
Table 3 Inpatient care at 3 months

\begin{tabular}{lllr}
\hline & $\begin{array}{l}\text { Point-of-care } \\
\mathbf{N}=\mathbf{1 1 2 5}\end{array}$ & $\begin{array}{l}\text { Standard care } \\
\mathbf{N}=\mathbf{1 1 1 8}\end{array}$ & p Value \\
\hline Days in hospital at any location & & & \\
$\mathrm{N}(\%)$ with no days & $607(54 \%)$ & $448(40 \%)$ & $<0.001$ \\
$\quad$ Mean days per patient & 1.8 & 1.7 & 0.815 \\
$\quad$ Total days (all patients) & 1961 & 1908 & \\
Days in coronary care & & & \\
$\mathrm{N}(\%)$ with days on coronary care & $50(4 \%)$ & $31(3 \%)$ & 0.041 \\
Mean days per patient & 0.17 & 0.09 & 0.033 \\
Total days (all patients) & 190 & 105 & \\
Days in intensive care & & & \\
N (\%) with days on intensive care & $8(1 \%)$ & $3(<1 \%)$ & 0.225 \\
Mean days per patient & 0.08 & 0.01 & 0.259 \\
Total days (all patients) & 76 & 14 & \\
\hline
\end{tabular}

because patients in the point-of-care arm who were admitted to hospital tended to accrue more inpatient days. Point-of-care assessment was also associated with a small increase in coronary care admission and chest pain-related outpatient followup. These findings suggest that point-of-care assessment changes the emergency department disposition of patients with undiagnosed chest pain and may reduce inpatient bed turnover, but does not reduce inpatient bed occupancy.
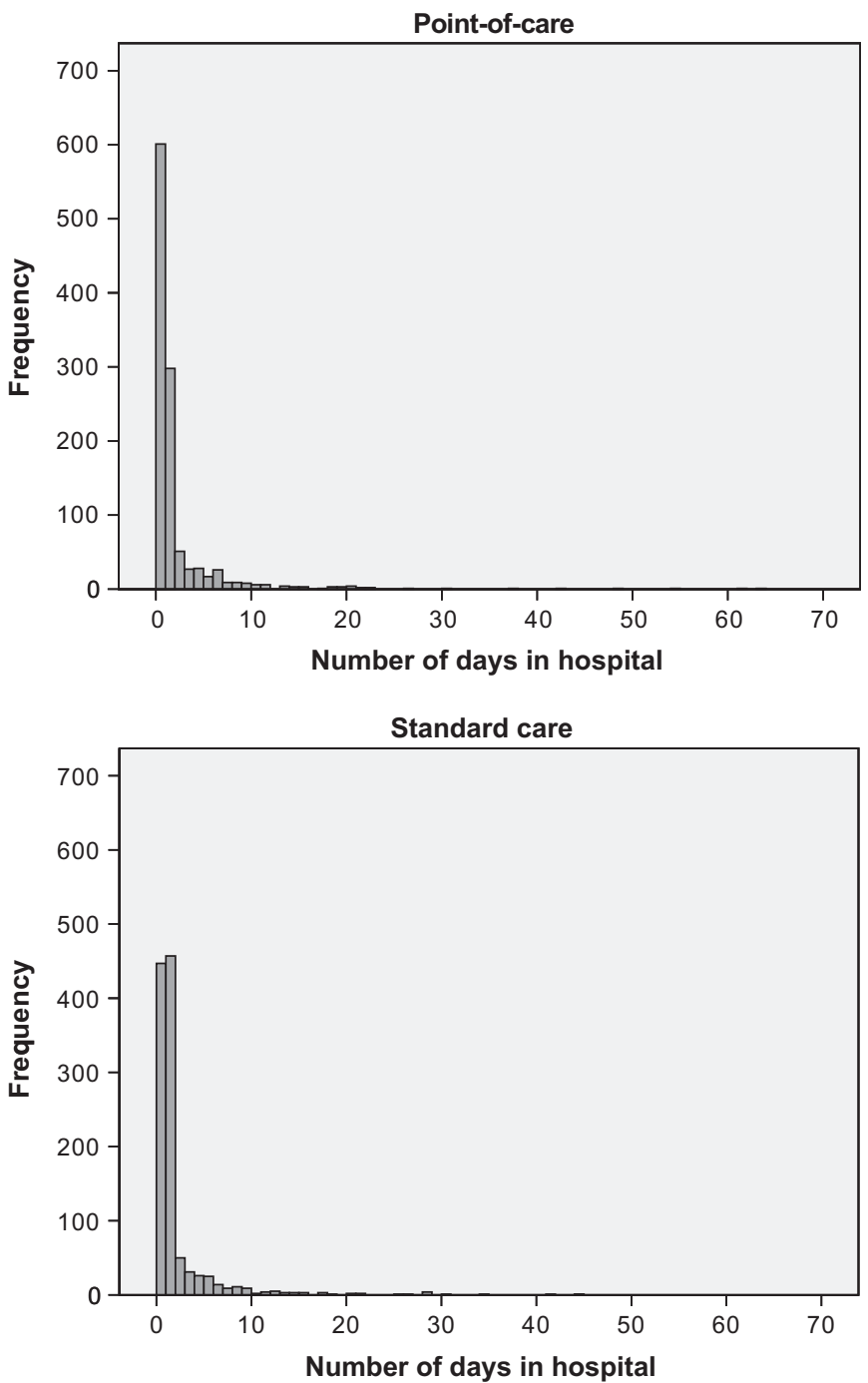

Figure 3 Histograms of number of inpatient days.
Table 4 Cardiac interventions, emergency department attendances, admissions and outpatient reviews

\begin{tabular}{llll}
\hline & $\begin{array}{l}\text { Point-of-care } \\
\mathbf{N}=\mathbf{1 1 2 5}\end{array}$ & $\begin{array}{l}\text { Standard care } \\
\mathbf{N}=\mathbf{1 1 1 8}\end{array}$ & p Value \\
\hline N (\%) needing thrombolysis & $1(<1 \%)$ & $2(<1 \%)$ & 0.624 \\
N (\%) needing PCI & $29(3 \%)$ & $29(3 \%)$ & 1.000 \\
N (\%) needing emergency PCI & $7(1 \%)$ & $12(1 \%)$ & 0.260 \\
N (\%) needing CABG & $11(1 \%)$ & $5(<1 \%)$ & 0.209 \\
N (\%) of emergency department & $140(12 \%)$ & $138(12 \%)$ & 0.949 \\
attendances & $107(10 \%)$ & $103(9 \%)$ & 0.828 \\
N (\%) of chest pain related emergency \\
department attendances
\end{tabular}

admissions*

$\mathrm{N}(\%)$ with any outpatient attendance

$\mathrm{N}(\%)$ with a chest pain related

$334(30 \%) \quad 322(29 \%)$

0.676

outpatient attendance

$241(21 \%) \quad 202(18 \%) \quad 0.05$

${ }^{*}$ Excluding admission at initial attendance.

$\mathrm{CABG}$, coronary artery bypass grafting; $\mathrm{PCl}$, percutaneous coronary intervention.

Interpretation of these findings depends upon one's perspective. For the patient, emergency physician or admitting physician point-of-care testing has the potentially beneficial effect of reducing the need for hospital admission. For the health service manager point-of-care testing may offer some benefit by reducing inpatient bed turnover but does not appear to reduce bed occupancy. An accompanying economic analysis (P Fitzgerald, SW Goodacre, E Cross, S Dixon, on behalf of the RATPAC research team, submitted July 2010) explores whether the potential benefits of point-of-care testing justify the additional costs.

Previous studies of point-of-care cardiac marker panels have focused on estimating accuracy for diagnosing myocardial infarction, but few have evaluated the effect on patient care. Newby et $a l^{9}$ demonstrated earlier identification of myocardial infarction than laboratory testing and Carragher et al ${ }^{10}$ showed expedited decision-making with turnaround times reduced by $55 \%$, but it was not clear whether these led to meaningful changes in patient care. $\mathrm{Ng}$ et $a l^{11}$ compared management with the panel to previous practice and showed a $40 \%$ reduction in coronary care unit admissions. Our finding of increased coronary care admissions may reflect differences between the healthcare systems or differences between the methods used. Historically controlled studies tend to overestimate the effects of intervention compared with randomised studies.

Table 5 Major adverse events

\begin{tabular}{|c|c|c|c|c|}
\hline & $\begin{array}{l}\text { Point-of- } \\
\text { care } \\
\mathrm{N}=1125\end{array}$ & $\begin{array}{l}\text { Standard } \\
\text { care } \\
\mathrm{N}=1118\end{array}$ & OR $(95 \% \mathrm{Cl})^{*}$ & p Value* \\
\hline Any event & $36(3 \%)$ & $26(2 \%)$ & $1.31(0.78$ to 2.20$)$ & 0.313 \\
\hline Death & $6(1 \%)$ & $2(<1 \%)$ & $3.4(0.7$ to 17.3$)$ & 0.142 \\
\hline $\begin{array}{l}\text { Non-fatal myocardial } \\
\text { infarction }\end{array}$ & $5(<1 \%)$ & $5(<1 \%)$ & $0.9(0.3$ to 3.2$)$ & 0.903 \\
\hline $\begin{array}{l}\text { Hospitalisation for acute } \\
\text { coronary syndrome (without } \\
\text { myocardial infarction) }\end{array}$ & $18(2 \%)$ & $9(1 \%)$ & $1.8(0.8$ to 4.1$)$ & 0.149 \\
\hline Life threatening arrhythmia & $6(1 \%)$ & $2(<1 \%)$ & $3.2(0.6$ to 15.9$)$ & 0.160 \\
\hline $\begin{array}{l}\text { Emergency } \\
\text { revascularisation }\end{array}$ & $10(1 \%)$ & $14(1 \%)$ & $0.7(0.3$ to 1.5$)$ & 0.324 \\
\hline
\end{tabular}

${ }^{*}$ Adjusted for age, gender and known coronary heart disease. 
Table 6 Major adverse events

\begin{tabular}{|c|c|c|c|c|}
\hline Age and gender & Study group & Testing at initial presentation & Working diagnosis & Adverse event \\
\hline 43 , female & Point-of-care & $\begin{array}{l}\text { Point-of-care tests negative, taken } 505 \\
\text { and } 600 \text { min after worst pain }\end{array}$ & Musculoskeletal pain & Hospitalisation for ACS 50 days later \\
\hline 63 , male & Point-of-care & $\begin{array}{l}\text { Point-of-care tests negative, taken } 721 \\
\text { and } 824 \text { min after worst pain }\end{array}$ & Musculoskeletal pain & Hospitalisation for ACS 1 day later \\
\hline 64 , female & Standard care & $\begin{array}{l}\text { Troponin negative } 1606 \text { min after worst } \\
\text { pain }\end{array}$ & Angina no ACS & Non-fatal MI 32 days later \\
\hline 78 , female & Point-of-care & $\begin{array}{l}\text { Point-of-care tests negative, taken } 800 \\
\text { and } 900 \text { min after worst pain }\end{array}$ & Gastro-oesophageal pain & $\begin{array}{l}\text { Died from metastatic pancreatic } \\
\text { carcinoma } 75 \text { days later }\end{array}$ \\
\hline 78, male & Point-of-care & $\begin{array}{l}\text { CK-MB and myoglobin negative, troponin } \\
0.06 \text { and } 0.07 \text { at } 909 \text { and } 1005 \text { min after } \\
\text { worst pain }\end{array}$ & Angina no ACS & $\begin{array}{l}\text { Life-threatening arrhythmia (SVT) } 48 \text { days } \\
\text { later }\end{array}$ \\
\hline
\end{tabular}

ACS, acute coronary syndrome; CK-MB, creatine kinase, myocardial type; MI, myocardial infarction; SVT, supraventricular tachycardia.

Randomised trials have compared the use of point-of-care and laboratory troponin assays. Renaud et $a l^{18}$ showed that point of care troponin testing in an emergency department reduced time to anti-ischaemic therapy and physician notification of troponin results, but did not change emergency department length of stay or patient outcomes. Ryan et al ${ }^{19}$ evaluated point-of-care troponin testing in four emergency departments and found that the effect varied between settings, with length of stay in the emergency department being increased in one hospital and decreased in another. These studies only evaluated the impact of point-of-care technology, whereas RATPAC evaluated the effect of point-of-care testing in a rapid rule-out protocol.

Our study has a number of strengths and weaknesses. Individual patient randomisation ensured allocation concealment and allowed an unbiased comparison of the intervention with standard care. Participation of six varied hospitals ensured that findings are generalisable across a range of settings. An important limitation is that the trial was not powered to detect potentially important differences in the adverse event rate. The overall adverse event rate was very low and most events occurred in patients admitted after initial assessment. Only one of the five adverse events in patients who were initially discharged home occurred within 1 month of recruitment, so there is little evidence of significant missed pathology. Furthermore, point-of-care testing was performed relatively late in this case so admission for

\section{What is already known on this subject}

- Chest pain due to suspected myocardial infarction is responsible for a substantial and increasing number of emergency department attendances and hospital admissions.

- A point-of-care cardiac biomarker panel consisting of CK-MB, myoglobin and troponin can safely rule out myocardial infarction in patients with acute chest pain within 90 min of presentation to hospital.

\section{What this study adds}

- Using the point-of-care panel increases the proportion of patients successfully discharged after emergency department assessment and reduces the median length of stay.

- Using the point-of-care panel does not alter the mean length of stay or hospital days, and increases the use of coronary care. a 12 -h troponin is unlikely to have yielded a positive result. Another limitation is that clinician behaviour may have been influenced by participation in the trial, with perhaps more cautious management of patients in either, or both, study groups. This may be reflected in the lower than anticipated rate of discharge in the control group. This could have been addressed by using cluster randomisation, albeit with associated problems of reduced statistical power and loss of allocation concealment. Finally, it should be emphasised that this is a pragmatic evaluation of point-of-care panel assessment in which patients were selected on the basis of clinical and ECG characteristics and decision-making was ultimately at the discretion of the clinician. The biomarker panel was used to augment, and not replace, clinical assessment.

In summary, we have shown that use of the point-of-care cardiac marker panel safely reduced hospital admissions but did not alter the mean length of hospital stay or inpatient days. The implications for practice will depend upon whether avoiding hospital admission is important to patients and the hospital, and the findings of the economic analysis undertaken alongside this trial (P Fitzgerald, SW Goodacre, E Cross, S Dixon, on behalf of the RATPAC research team, submitted July 2010)

Acknowledgements The authors would like to thank Margaret Jane for her invaluable clerical assistance; David Gaze at St George's Hospital, London, for his helpful advice and assistance with all things blood tube related; staff involved at the NHS sites for all their hard work and participants for their involvement; Francis Morris for advice on emergency department data and Siemens for providing the Stratus CS machines and technical support and assistance.

The RATPAC Research Team Charlotte Arrowsmith (RATPAC research nurse, Derriford Hospital, Plymouth); Julian Barth (consultant in chemical pathology, Leeds General Infirmary/co-applicant); Jonathan Benger (professor of emergency care, University of the West of England/co-applicant); Mike Bradburn (senior medical statistician, Clinical Trials Research Unit, University of Sheffield); Simon Capewell (professor of epidemiology, University of Liverpool/co-applicant); Tim Chater (database manager, Clinical Trials Research Unit, University of Sheffield); Tim Coats (professor of emergency medicine/co-applicant); Paul Collinson (consultant in chemical pathology, St George's Hospital, London/co-applicant); Cindy Cooper (director, Clinical Trials Research Unit, University of Sheffield); Mandy Cooper (RATPAC research nurse, Leicester Royal Infirmary); Judy Coyle (RATPAC research nurse, Edinburgh Royal Infirmary); Liz Cross (trial manager, Health Services Research, University of Sheffield): Simon Dixon (professor of health economics, health economics and decision science/co-applicant); Patrick Fitzgerald (research fellow, health economics and decision science, University of Sheffield); Emma Gendall (RATPAC research nurse, Frenchay Hospital, Bristol); Steve Goodacre (professor of emergency medicine, Health Services Research, University of Sheffield/chief investigator); Emma Goodwin (RATPAC research nurse, Barnsley Hospital); Alasdair Gray (consultant in emergency medicine, Royal Infirmary of Edinburgh/co-applicant); Alistair Hall (professor of clinical cardiology, University of Leeds/co-applicant); Kevin Hall (RATPAC research nurse, Barnsley Hospital); Taj Hassan (consultant in emergency medicine, Leeds General Infirmary/co-applicant); Julian Humphrey (consultant in emergency medicine, Barnsley Hospital); Steven Julious (senior lecturer in medical statistics, Medical Statistics Group, Health Services Research, University of Sheffield/co-applicant); Jason Kendall (consultant in emergency medicine, Frenchay Hospital, Bristol); Vanessa Lawlor 
(RATPAC research nurse, Frenchay Hospital, Bristol): Sue Mackness (RATPAC research nurse, Leicester Royal Infirmary); Yvonne Meades (RATPAC research nurse, Leeds General Infirmary): David Newby (professor of cardiology, University of Edinburgh/co-applicant); Dawn Newell (RATPAC research nurse, Leicester Royal Infirmary); Doris Quartey (RATPAC research nurse, Leeds General Infirmary); Karen Robinson (RATPAC research nurse, Leicester Royal Infirmary); Glen Sibbick (RATPAC research nurse, Leicester Royal Infirmary); Jason Smith (consultant in emergency medicine, Derriford Hospital, Plymouth); Roz Squire (RATPAC research nurse, Derriford Hospital, Plymouth).

Trial Steering Committee Simon Carley, consultant in emergency medicine, Manchester Royal Infirmary (independent member); Paul Collinson, consultant in chemical pathology, St George's Hospital, London (co-applicant); Liz Cross, research associate, Health Services Research, University of Sheffield (trial manager); Sue Dodd, CHD emergency and acute care manager (vascular programme) Department of Health (independent member); Marcus Flather, director, Clinical Trials and Evaluation Unit, Royal Brompton Hospital, London (chair); Steve Goodacre, professor of emergency medicine, Health Services Research, University of Sheffield (chief investigator); Sara Hilditch, statistician, director of Statistical Services Unit, Sheffield University (independent member); Enid Hirst (lay representative); Richard Hudson, quality assurance manager, Research Office, Academic Division, University of Sheffield (sponsor representative); Jason Kendall, consultant in emergency medicine, Frenchay Hospital, Bristol (investigator representative); Rebecca Whitlock-Moss, programme manager, National Institute for Health Research Health Technology Assessment (funder representative).

Data Monitoring Committee John Greenwood, senior lecturer/consultant cardiologist, Academic Unit of Cardiovascular Medicine, Leeds General Infirmary (independent clinician); Jon Nicholl, professor of health services research, University of Sheffield (acting chair); Helen Thorpe, principal statistician, Clinical Trials Research Unit, University of Leeds (chair and independent statistician); William Townend, consultant in emergency medicine, Hull Royal Infirmary (independent clinician).

Disclaimer The views and opinions expressed therein are those of the authors and do not necessarily reflect those of the National Institute for Health Research Health Technology Assessment.

Funding The RATPAC trial was funded by the National Institute for Health Research Health Technology Assessment programme (no 06/302/19) and sponsored by the University of Sheffield. The study funders had no role in study design, in the collection, analysis and interpretation of data, in the writing of the report or in the decision to submit the paper for publication. The researchers were independent of the study funders. All authors, external and internal, had full access to all of the data (including statistical reports and tables) in the study and can take responsibility for the integrity of the data and the accuracy of the data analysis.

\section{Competing interests None.}

Ethics approval The study was granted ethics approval by Leeds East Research Ethics Committee and review was provided by the local research ethics committee at each participating centre.

Contributors The article was written on behalf of the RATPAC Research Team. SWG conceived and designed the study, analysed and interpreted the data, wrote the first and subsequent drafts of the paper and approved the final version, and is the guarantor for the paper. MB analysed and interpreted the data, contributed to redrafting of the paper and approved the final version. LC managed the RATPAC project, collected data, contributed to redrafting of the paper and approved the final version. PC helped to conceive and design the study, helped to analyse and interpret the data, contributed to redrafting of the paper and approved the final version. AG helped to conceive and design the study, helped to analyse and interpret the data, contributed to redrafting of the paper and approved the final version. ASH helped to conceive and design the study, contributed to redrafting of the paper and approved the final version.

Provenance and peer review Not commissioned; externally peer reviewed.

\section{REFERENCES}

1. Robinson P. Are hospital admissions out of control? Caspe Healthcare Knowledge Systems (CHKS), London, UK 2009

2. Goodacre S, Cross E, Arnold J, et al. The health care burden of acute chest pain. Heart 2005:91:229-30.

3. National Institute for Health and Clinical Excellence. Guidance for the management of acute chest pain. http://www.nice.org.uk/guidance/index.jsp? action $=$ download\&o $=47031$ (accessed 22 Jan 2010)

4. Bertrand ME, Simoons ML, Fox KA, et al. Task Force on the Management of Acute Coronary Syndromes of the European Society for Cardiology. Management of acute coronary syndromes in patients presenting without ST elevation. Eur Heart $J$ 2002;23:1809-40.

5. Reichlin T, Hochholzer W, Bassetti S, et al. Early diagnosis of myocardial infarction with sensitive cardiac troponin assays. N Engl J Med 2009;361:858-67.

6. Keller T, Zeller T, Peetz D, et al. Sensitive troponin I assay in early diagnosis of acute myocardial infarction. N Engl J Med 2009;361:868-72.

7. McCord J, Nowak RM, McCullough PA, et al. Ninety-minute exclusion of acute myocardial infarction by use of quantitative point-of-care testing of myoglobin and troponin I. Circulation 2001;104:1483-8.

8. Apple FS, Christensen RH, Valdes R, et al. Simultaneous rapid measurement of whole blood myoglobin, creatinine kinase MB and cardiac troponin I by the triage cardiac panel for detection of myocardial infarction. Clin Chem 1999;45:199-205.

9. Newby LK, Storrow AB, Gibler WB, et al. Bedside multimarker testing for risk stratification in chest pain units: the CHECKMATE Study. Circulation 2001;103:1832-7.

10. Caragher TE, Fernandez BB, Jacobs $\mathrm{FL}$, et al. Evaluation of quantitative cardiac biomarker point of care testing in the emergency department. J Emerg Med 2002;22:1-7.

11. Ng SM, Krishnaswamy P, Morissey R, et al. Ninety-minute accelerated critical pathway for chest pain evaluation. Am J Cardiol 2001;88:611-17.

12. Hamilton AJ, Swales LA, Neill J, et al. Risk stratification of chest pain patients in the emergency department by a nurse utilizing a point of care protocol. Eur J Emerg Med 2008;15:9-15

13. Rathore S, Knowles P, Mann APS, et al. Is it safe to discharge patients from accident and emergency using a rapid point of care triple cardiac marker test to rule out acute coronary syndrome in low to intermediate risk patients presenting with chest pain? Eur J Int Med 2008;19:537-40.

14. Straface AL, Myers $\mathrm{JH}$, Kirchick HJ, et al. A rapid point-of-care cardiac marker testing strategy facilitates the rapid diagnosis and management of chest pain patients in the emergency department. Am J Clin Pathol 2008:129:788-95.

15. Burtonwood C, Halloran S. Report 06020: three point of care devices for troponin measurement. NHS Purchasing and Supply Agency: Centre for Evidence-based Purchasing, London, UK 2006.

16. Thygesen K, Alpert JS, White HD. Joint ESC/ACCF/AHA/WHF Task Force for the Redefinition of Myocardial Infarction. Universal definition of myocardial infarction. $J$ Am Coll Cardiol 2007:50:2173-95.

17. Goodacre S, Nicholl J, Dixon S, et al. Randomised controlled trial and economic evaluation of a chest pain observation unit compared with routine care. BMJ 2004;328:254-7.

18. Renaud B, Maison P, Ngako A, et al. Impact of point-of-care testing in the emergency department evaluation and treatment of patients with suspected acute coronary syndromes. Acad Emerg Med 2008;15:216-24.

19. Ryan RJ, Lindsell CJ, Hollander JE, et al. A multicenter randomized controlled tria comparing central laboratory and point-of-care cardiac marker testing strategies: the Disposition Impacted by Serial Point of Care Markers in Acute Coronary Syndromes (DISPO-ACS) Trial. Ann Emerg Med 2009:53:321-8. 